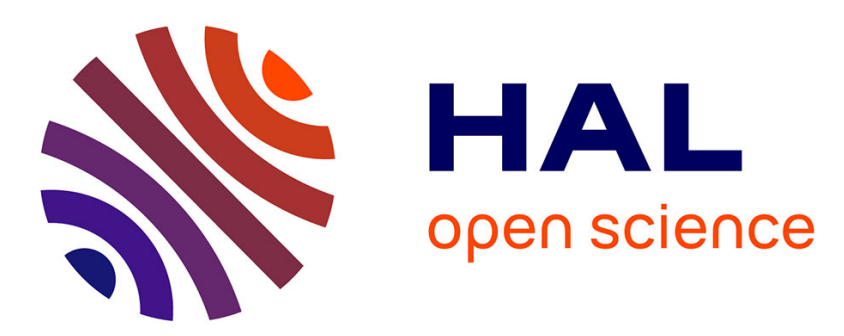

\title{
Microstructures and mechanical properties of an Osprey aluminium 7000 alloy
}

L. Cottignies, Y. Brechet, M. Audier, F. Livet, F. Louchet, P. Sainfort

\section{To cite this version:}

L. Cottignies, Y. Brechet, M. Audier, F. Livet, F. Louchet, et al.. Microstructures and mechanical properties of an Osprey aluminium 7000 alloy. Journal de Physique IV Proceedings, 1993, 03 (C7), pp.C7-215-C7-218. 10.1051/jp4:1993732 . jpa-00251965

\section{HAL Id: jpa-00251965 https://hal.science/jpa-00251965}

Submitted on 1 Jan 1993

HAL is a multi-disciplinary open access archive for the deposit and dissemination of scientific research documents, whether they are published or not. The documents may come from teaching and research institutions in France or abroad, or from public or private research centers.
L'archive ouverte pluridisciplinaire HAL, est destinée au dépôt et à la diffusion de documents scientifiques de niveau recherche, publiés ou non, émanant des établissements d'enseignement et de recherche français ou étrangers, des laboratoires publics ou privés. 


\title{
Microstructures and mechanical properties of an Osprey aluminium 7000 alloy
}

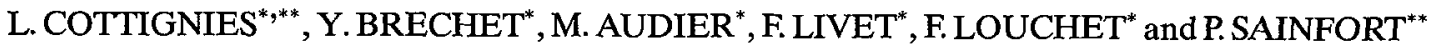 \\ ${ }^{*}$ LTPCM/ENSEEG, Domaine Universitaire de Grenoble, BP. 75, 38402 St Martin d'Hères cedex, France \\ ${ }^{* *}$ CRV Pechiney, BP. 25, Centralp, 38340 Voreppe, France
}

\begin{abstract}
An alioy from the 7000 serie obtained by the Osprey process has been studied both from the microstructural (TEM, SAXS) and from the mechanical viewpoint. The modelling of the mechanical properties and of their anisotropy was performed using both models from physical metallurgy and a self consistent eslastoplastic model.
\end{abstract}

\section{Introduction}

The OSPREY process allows the elaboration of alloys with a high concentration in alloying elements without having macroscale segregations (1). As a consequence such alloys may have very interesting hardening potentialities. The alloy we are considering in the present work belongs to the 7000 series. $\mathrm{Cu}, \mathrm{Mg}$ and $\mathrm{Zn}$ are the elements responsible for the structural hardening, $\mathrm{Cr}, \mathrm{Zr}$ and $\mathrm{Mn}$ create dispersoids which act as antirecrystallisant. Even if the 7000 series alloys have since their discovery in 1917 motivated a number of work, the microstructure and the properties of these special compositions have yet recieved very little detailed studies $(2,3)$.The quantitative characterization necessary to understand the mechanical properties of those unconventional alloys was achieved by a detailed study in TEM and SAXS. Then we use standard models of physical metallurgy plus the self consistent approach to the deformation of the polycristal in order to predict relations between microstructure and macroscopic properties involving also the crystallographic texture. Special attention is given to the anisotropy of the mechanical properties.

1)The materials and their heat treatments. Experimental results concerning the microstruture and the mechanical properties.

The alloy after its elaboration by the OSPREY process has undergone an extrusion, an homogeneisation treatment of 8 hours at $475^{\circ} \mathrm{C}$, and a solid solution treatment of 2 hours at $470^{\circ} \mathrm{C}$. The subsequent ageing heat treatments that we have extensively studied are : T4 : Room temperature ageing, T6, T7, TX and TY ageing at 
$105^{\circ} \mathrm{C}$ during $32 \mathrm{~h}, 128 \mathrm{~h}, 500 \mathrm{~h}, 1400 \mathrm{~h}$ respectively. Table 1 gives the characteristics of the microstructure and Table 2 the mechanical properties for the various heat treatments.

\begin{tabular}{|l|c|c|c|c|c|}
\hline condition & T4 & T6 & T7 & TX & TY \\
\hline precipitate radius $(\AA)$ & 8,5 & 14,2 & 16,6 & 29 & 32 \\
\hline volume fraction $(\%)$ & 10 & 10 & 10 & 10 & 10 \\
\hline
\end{tabular}

Table 1: characteristics of the microstructure

\begin{tabular}{|l|c|c|c|c|}
\hline condition & YS (L) & YS (TL) & UTS (L) & UTS (TL) \\
\hline T4 & 598 & $549 \pm 9$ & $840 \pm 14$ & $696 \pm 39$ \\
\hline T6 & $771 \pm 3$ & $662 \pm 2$ & $833 \pm 30$ & $755 \pm 14$ \\
\hline T7 & $774 \pm 0$ & $674 \pm 3$ & $819 \pm 46$ & $754 \pm 26$ \\
\hline TX & 750 & $685 \pm 2$ & $830 \pm 42$ & $761 \pm 20$ \\
\hline TY & 700 & $665 \pm 3$ & $853 \pm 20$ & $764 \pm 4$ \\
\hline
\end{tabular}

Table 2: mechanical characteristics in the long (L) and transverse (TL) direction.

The characterisation of the microstructure has been carried on at different scales :

- The average grain size was $5 \mu \mathrm{m}$ with an aspect ratio of 3 (Fig 1a), the grains being elongated in the extrusion direction .

-The intragranular precipitation was studied both in TEM and by SAXS .

The phases which were identified were $\mathrm{Al}_{3} \mathrm{Zr}$, in very low volume fraction and which has negligible contribution to the hardening of the alloy, and several phases containing $\mathrm{Mg}$, $\mathrm{Zn}$ and $\mathrm{Cu}$ which are mainly the ones responsible for the high elastic limit (the $\eta^{\prime}$ phase with a misfit of less than $1 \%$ and a cubic phase which can be identified from the diffraction patterns : it has the KS relations with the matrix and do not seem to be coherent otherwise) These phases appear as thick platelets .

At short times heat treatments (T4,T6, T7) the $\eta^{\prime}$ phases are dominant, whereas for the longer heat treatments (TX, TY) the cubic phase is dominant. A small angle Xray scattering analysis provides some extra informations concerning the fine precipitation : the volume fraction of the precipitates was found to be constant, and their volume to scale linearly with timein all the heat treatments which indicates that the kinetics of precipitation is already in the coarsening regime.

-The texture measurements obtained from Xrays experiments show a marked fiber texture 
-The mechanical properties were measured on an INSTRON machine 1185 . The yieid stress and the work hardening behaviour were measured for samples in the long and in the long transverse directions.

\section{2)Modelling of the average yield stress}

The models of physical metallurgy allow one to derive the critical resolved shear stress in a plane as a function of the microstructure. The complementary aspect of modelling the mechanical properties is the scale transition from the single crystal to the polycrystal :In order to do so we have used the elastoplastic model developped by Berveiler and Lipinski (4). In this work our purpose was to use jointly the two approaches in order to have a microstructure related description of the mechanical properties and of their anisotropy.

The first step in the modelling is to describe the average properties . Using the self consistent approach we have therefore determined an average Taylor's factor for the crystallographic texture which has allowed us to estimate the value of the critical shear stress which would correspond to the observed yield stress .

The grain size effect for hard aluminium alloys is known to be a small contribution to their strength (5). In our case we could estimate the contibution to the resolved shear stress due to the grain size effect to $20 \mathrm{MPa}$. The solid solution contribution to hardening is mainly due to $\mathrm{Zn} \mathrm{Cu}$ and $\mathrm{Mg}$. Using an empirical model due to Noble (6) ,immediatly after quench when all the atoms are in solid solution, one would find a contribution to the resolved shear stress of $2.3 \mathrm{MPa}$. We can therefore reasonably consider that in our alloys the solid solution hardening is negligible .

The major contribution to hardening comes therefore from the precipitation of the $\eta^{\prime}$, and cubic phases. As we know the volume fraction and the size of the precipitates, we can clearly show that the Orowan critical shear stress is much larger than the observed values. As a consequence we can assume that the precipitates are probably sheared. In Al $\mathrm{Zn}$ alloys, it is known that the hardening comes from misfitting precipitates (7). In that case one expects a functional dependence in (t.R) ${ }^{1 / 2}$.(Where $R$ is the radius and $f$ the volume fraction of the precipitates). Performing this analysis on the increasing part of our curve ( T4 and T6 heat treatments), we find that the hardening indeed behaves as $\mathrm{R}^{1 / 2}$ and would correspond to a misfit of $3.5 \%$ which is comparable to the one associated with GP zones in Al Zn (but somewhat larger, $1.5 \%$ in Al Zn binary alloys ). The slight decrease of the CRSS for longer ageing times comes from the transition to the cubic phases.

\section{3)The physical causes for the anisotropy of the mechanical properties}

The non relaxed internal stresses coming from the processing contribute to a value of less than $15 \mathrm{MPa}$ as can be checked by a Baushinger test .

If one considers the alloy with the T7 heat treatment (i. e. the overaged alloy ), the anisotropy that one computes from the self consistent elastoplastic model is in good agreement with the experimental one.

If one considers now the underaged states, the anisotropy is much larger than the one expected from the texture effects and the discrepancy is the larger for the shortest heat treatments. We can explain qualitatively this discrepancy remarking that 
the precipitation itself shows an anisotropy as can be seen from the electron diffraction patterns : the diffraction pattern does not present the 6 fold symetry as far as intensity are concerned which means that the precipitates are not evenly distributed on equivalent matrix habit planes. The physical reason for this symetry breakdown can be explained as follows : while quench occurs, some thermal stresses develop which leads to a triaxial state of traction inside the bar $(B)$. This traction stress is above the yield stress and leads to a plastification and therefore to the proliferation of dislocations. When the heat treatment is subsequently made the precipitates which have a misfit with the aluminium matrix will precipitate preferentially on those quench dislocations. As a consequence the various families of precipitates will not be equivalent (which explains the lack of rotationnal symetry in the intensity of the diffraction patterns ) and the precipitation hardening is going to be anisotropic. This amounts to have enhanced the anisotropy due to texture because the precipitates will appear preferentially on the planes which have yielded during the quench. The net effect can be seen as an extra large effective work hardening resulting from this predeformation due to the quench. This idea can therefore explain the high anisotropy of the underaged states. When the ageing sequence lasts longer some coarsening of the precipitates will take place which will tend to reduce the anisotropy of the precipitation and that will be especially true when the transition to the non coherent cubic phase has taken place. As a consequence the diffraction pattern becomes more 6 fold symmetric and the anisotropy can then be completely explained from the texture as can be seen in the TY heat treatment.

\section{Conclusions}

We have shown in this paper how a detailed and quantitative study of the microstructural characteritics of an industrial alloy (Osprey 7000 series) can be used to rationalize the observed mechanical properties. The conceptual tools necessary to fulfill this program have been the use of standard physical metallurgy models coupled with a self consistent elastoplastic model. It is the belief of the authors that such methods can be useful not only to predict the static mechanical properties of the alloys, but also as an aid to designing improved processing routes in the conception of hard aluminium alloys .

\section{Acknowledgements:}

It is a pleasure for the authors to acknowledge useful discussions with David Embury and Gilles Canova.

\section{References}

(1)R.W.Evans,A.G.Leatham,R.G.Brooks Powder metallurgy,28,13,(1985)

(2)M.De Sanctis, Mat.sc. Eng.A141,103,(1991)

(3)J.Duszcyk,JL.Estrada,TLJ DeHahn, A.G.Leatham, AJW.Ogilvy, International conference on powder metallurgy aerospace materials, Lucerne (1986), p23

(4)P.Lipinski, J.Krier, M.Berveiller, Rev. physique appliquée, 25, 361, (1990)

(5)R.W.Armstrong Met .Trans AIME, 1, 1169, (1970)

(6)F.W.Noble, F.J.Harris, K.Dinsdale, Metal science, 16, 425, (1982)

(7)M.Wit, V.Gerold, Scripta Met, 3, 371, (1969)

(8)P.Jeanmart, B.Dubost, J.Bouvaist, "les contraintes résiduelles dans les pièces en alliage d'aluminium" éditions de l'usine nouvelle, (1986) 